\title{
Protein Sparing Effect of Lipid in Diets for Common Carp(Cyprinus carpio)
}

\section{Ze FAN ${ }^{\mathrm{a}}$, Jinghui $\mathrm{LI}^{\mathrm{b}}$, Zhenyan $\mathrm{CHENG}^{\mathrm{c}}$, Baolong ZHANG ${ }^{\mathrm{d}}, \mathrm{Mu} \mathrm{QU}^{\mathrm{e}}$, Jinhui SUN ${ }^{f}$, Dongqing $\mathrm{BAI}^{\mathrm{g}}$ and Xiuting QIAO ${ }^{\mathrm{h}_{*}}$}

\author{
Tianjin Key Lab of Aqua-Ecology and Aquaculture, College of Fisheries, Tianjin Agricultural \\ University, Tianjin 300384, P.R. China. \\ adankey1534417945@163.com, bLJH11251110@163.com, chengzhenyan2005@126.com, \\ dzbl136520@tom.com, equ310901543@yeah.net, jihsun1008@163.com, \\ gbaidongqing@tjau.edu.cn, ${ }^{\mathrm{h}} \mathrm{qxt65} @$ sohu.com
}

\begin{abstract}
Keywords: Common Carp; Growth; Activities of related lipid metabolic enzymes; Gene expressions Abstract. This experiment was conducted to evaluate the effects of dietary lipid level on growth performance, activities, and gene expression of related lipid metabolism enzyme of common carp (initial average weight $(36.12 \pm 1.18) \mathrm{g}$. Five experimental diets with increasing lipid levels of $2.1 \%$, $4.0 \%, 5.8 \%, 7.6 \%, 9.4 \%$ were fed to triplicate groups of fish for 9 weeks. The results showed that the weight gain (WG) and special growth ratio (SGR) were significantly higher in fish fed with diets containing $7.6 \%$ lipid than that fed with $9.4 \%$ lipid group $(P<0.05)$. Feed conversion ratio (FCR) was significantly lower in fish fed with diets containing 7.6\% lipid than that fed with diets containing 9.4\% lipid $(P<0.05)$. The highest protein efficient ratio (PER) was observed in fish fed with diets containing $7.6 \%$ lipid. The activity of lipoprotein lipase (LPL), hepatic lipase(HL), and the general esterase (GE) all increased with the increase of dietary lipid levels, and the peak was found in fish fed with 9.4\% lipid diet. The increase of dietary lipid levels had a significant effect on the expression level of liver and kidney FAS and LPL mRNA $(P<0.05)$. After refeeding for $6 \mathrm{~h}$, the expression level of liver FAS mRNA significantly declined in each group $(P<0.05)$. After refeeding for $12 \mathrm{~h}$, the expression level of liver LPL mRNA significantly increased in each group $(P<0.05)$. Those results indicated that the diet containing $29.2 \%$ protein and $7.6 \%$ lipid was the best level for the growth of common carp.
\end{abstract}

\section{Introduction}

As one of the important nutrients of fish, lipid is not only the solvent of lipid-soluble nutrients, but also the elements of animal tissues and provide essential lipid acids for fish. Besides, lipid, as main energy materials, are able to increase digestible energy content of the dietary and reduce part of protein used as energy consumption, thereby making it synthesize body protein more efficiently and promote growth more fully, which is the saving function of lipid to protein, so lipid plays an important role on maintaining the fish growth, development and normal physiological metabolism. Some studies have shown that too high or too low dietary lipid levels will have an impact on fish. High dietary lipid levels will lead to excessive fish lipid deposition and decrease in disease resistance, and low levels can cause fish metabolism disorder [1-3]. Therefore, whether dietary lipid level is appropriate or not have an effect on the growth of fish.

First of all, these effects can be confirmed from a number of major changes and physical growth indicators. Han Guangming [4] found when weight gain and specific growth rate was regarded as the main reference, the appropriate lipid levels of Yoshitomi tilapia dietary drawn in the range of 5.69-7.67\%, and then low-lipid group and high-lipid group and specific growth rate decreased. Next, at the same time dietary lipid levels also can affect the fish body and muscle compositions. Related research shows that in many fish there are a positive correlation between dietary lipid levels and lipid of fish body and muscle [5,6]. Also dietary lipid levels will have an impact on moisture, ash, protein content of fish body and muscle, and especially effects on protein content also reflect the saving function of lipid to protein from the side [7]. 
At present, the saving function of lipid of carp dietary to protein also had rather extensive research, and most concentrated on the impacts of dietary lipid levels on fish growth, digestive enzyme activity, immunity and so on, but the impacts of dietary lipid levels on carp lipid metabolism, especially the impacts on the expression of FAS and LPL which are key enzymes in lipid metabolism were relatively rare in previous studies.

This experiment was conducted to evaluate the effects of dietary lipid level on growth performance, body composition, activities, and gene expression of related lipid metabolism enzyme of common carp. These studies can help us clarify the use transformation capabilities for lipid of carp and explore the optimal lipid level of carp dietary to reduce feed costs, improve feed efficiency and improve environmental benefits, which will not only provide a theoretical reference for the study and use of low-nitrogen dietary, but also further explore the mechanism of action of enzymes related to lipid metabolism and provide the referential data for the study on molecular regulation of lipid metabolism mechanism of fish.

\section{Materials and methods}

\section{Experimental materials}

Experimental fish and procedure

Common carp were provided by Tianjin Huan Xin aquatic breeding farm. The feeding trials was conducted at Tianjin Tianxiang Aquaculture company. After acclimation, 900 commom carps (average weight $36.12 \pm 1.18 \mathrm{~g}$ ) were randomly divided into 15 cages (60 fish per cage). The following 5 groups (three cages per group) were used in the experiment. The fish were fed the Experimental diets for 9 weeks. During the experiment, the fish were fed three times per day at 9:00 and 15:30. Water temperature was measured every day, and water quality was measured every week. The water temperature was $(29 \pm 1.1){ }^{\circ} \mathrm{C}, \mathrm{pH} 7.8 \pm 0.2$.

\section{Experimental diet}

Fish meal, soybean meal, peanut meal and cotton meal were used as protein source, and soybean oil was used as lipid source. Five experimental diets with increasing lipid levels of $2.1 \%, 4.0 \%, 5.8 \%$, $7.6 \%, 9.4 \%$ and decreasing lipid levels of $32.0 \% 、 31.1 \%, 30.2 \%, 29.2 \%, 28.3 \%$ were fed to triplicate groups of fish for 9 weeks. All the feed ingredients were pulverizered by 40 mesh sieve. After mixing fully, sinking pellet feed $(2 \mathrm{~mm}$ pellet diameter) were made using a feed mill (MUZLMV4, Jiang Su Shepherd Group). Composition and nutrient levels of each group experimental diet are shown in Table 1.

Sample collection

Three fish per cage (nine fish per group) were randomly collected, weighed, killed and dissected at $24 \mathrm{~h}$ pasting of the 9-week feeding trials; liver , pancreas and kidneys and dorsal muscles above the lateral lines on both sides of the body were sampled and then immediately frozen at $-20^{\circ} \mathrm{C}$. Livers, pancreases and kidneys were used for determinations of activities of related metabolic enzymes. Dorsal muscles were used for determination of nutrient composition. The remaining fish are divided into two groups. After $48 \mathrm{~h}$ starvation, low-lipid group were fed with Diet 1 (32.0/2.1) and high-lipid group were fed with Diet 5 (28.3/9.4). And then, three fish per cages (nine fish per group) were randomly collected, killed and dissected at each of the following times: $48 \mathrm{~h}$ fasting, 3, 6, 12, 24 and $48 \mathrm{~h}$ after refeeding. Livers, pancreases and kidneys were sampled, immediately flash frozen in liquid nitrogen and then transferred to $-80^{\circ} \mathrm{C}$ for later isolation and quantification of FAS and LPL mRNA of livers, pancreases and kidneys. 
Table 1 Composition and nutrient levels of experimental diets (air-dry basis)

\begin{tabular}{|c|c|c|c|c|c|}
\hline \multirow{2}{*}{ Ingredients } & \multicolumn{5}{|c|}{ Diet No. } \\
\hline & Diet 1 & Diet 2 & Diet 3 & Diet 4 & Diet 5 \\
\hline Fish meal & 6 & 4.5 & 3 & 1.5 & 0 \\
\hline Soybean meal & 22 & 22 & 22 & 22 & 22 \\
\hline Peanut meal & 12 & 12 & 12 & 12 & 12 \\
\hline Cotton meal & 10 & 10 & 10 & 10 & 10 \\
\hline Rapeseed meal & 12 & 12 & 12 & 12 & 12 \\
\hline Cellulose & 2 & 1.5 & 1 & 0.5 & 0 \\
\hline DDGS & 3 & 3 & 3 & 3 & 3 \\
\hline Soybean oil & 0 & 2 & 4 & 6 & 8 \\
\hline Premix & 4 & 4 & 4 & 4 & 4 \\
\hline Wheat flour & 9 & 9 & 9 & 9 & 9 \\
\hline Wheat middlings & 10 & 10 & 10 & 10 & 10 \\
\hline Wheat bran & 10 & 10 & 10 & 10 & 10 \\
\hline Total & 100 & 100 & 100 & 100 & 100 \\
\hline \multicolumn{6}{|l|}{ Nutrient levels } \\
\hline Crude protein & 32.0 & 31.1 & 30.2 & 29.2 & 28.3 \\
\hline Crude lipid & 2.1 & 4.0 & 5.8 & 7.6 & 9.4 \\
\hline Gross energy /(MJ $/ \mathrm{kg})$ & 11.7 & 12.2 & 12.7 & 13.2 & 13.7 \\
\hline
\end{tabular}

\section{Experimental methods}

Determinations of growth parameters

On the first and last days of the experiment, the fish were weighed ( $\mathrm{W} \pm 0.01 \mathrm{~g}$ ) and measured (body length, $\mathrm{L} \pm 0.1 \mathrm{~cm})$. The data collected were used to calculate the following parameters:

Survival rate $=100 \% \times \mathrm{Nt} / \mathrm{N} 0$;

Weight growth rate $(\mathrm{WGR}, \%)=100 \% \times(\mathrm{Wt}-\mathrm{W} 0) / \mathrm{W} 0$

Specific growth rate $(\mathrm{SGR}, \% / \mathrm{d})=100 \% \times[\ln (\mathrm{Wt})-\ln (\mathrm{W} 0)] / \mathrm{t}$

Feed conversion ratio $(\mathrm{FCR})=\mathrm{F} /(\mathrm{Wt}-\mathrm{W} 0)$

Protein efficiency ratio $(\mathrm{PER}, \%)=100 \% \times(\mathrm{Wt}-\mathrm{W} 0) /(\mathrm{F} \times \mathrm{P})$

$\mathrm{HIS}(\%)=100 \% \times \mathrm{Wg} / \mathrm{Wt}$

$\mathrm{CF}(\%)=100 \% \times \mathrm{Wt} / \mathrm{Lt} 3$

Where $\mathrm{N}_{\mathrm{t}}$ and $\mathrm{N}_{0}$ are the final and initial body number, $\mathrm{W}_{\mathrm{t}}$ and $\mathrm{W} 0$ are the final and initial body weight $(\mathrm{g})$, t-time of rearing (days), L-fish body length $(\mathrm{cm})$, F-total feed intake $(\mathrm{g})$, P-content of dietary protein $(\mathrm{g})$ and $\mathrm{W}_{\mathrm{g}}$-liver weight $(\mathrm{g})$. 
Determinations of activities of related metabolic enzymes

Determinations of activities of total lipase in livers, pancreases and kidneys

Colorimetric method was used for determinations of activities of hepatic lipase and lipoprotein lipase. Their activity unit is defined as per hour per gram of $1 \mu \mathrm{mol}$ of free fatty acids produced by the liver and pancreas as an activity unit $(\mathrm{U} / \mathrm{g})$, wherein the total lipase activity = lipoprotein lipase activity + hepatic lipase activity. Lipase determination required kit purchased from Nanjing Jiancheng Bioengineering Institute.

Determinations of activities of fatty acid synthase in livers, pancreases and kidneys

Lipid acid synthase (FAS) activity unit is defined as $1 \mathrm{~g}$ liver and pancreatic enzyme NADPH oxidation of $14 \mathrm{nmol}$ of $(\mathrm{U} / \mathrm{g})$ per minute; their determination required kit were purchased from Nanjing Jiancheng Bioengineering Institute.

Determinations of FAS and LPL mRNA in livers, pancreases and kidneys

Primer Design

The forward and reverse primers used for PCR were designed based on the obtained partial sequence of FAS, LPL and $\beta$-actin of other fish. The primer sequences and the reaction parameters of PCR were described in Table 2 [8].

Table 2 Primers used in this study

\begin{tabular}{ccc}
\hline Primers & Forward and reverse primers (5' to 3') & PCR product size (bp) \\
\hline FAS & R: 5'-GAGTTTTCAGGGCGAGAC-3' & 709 \\
& F:-CCTCCACTTGGTTTCTCTC-3' 5'-CATCTGTTGGGTTACAGT-3' & 487 \\
LPL & R: 5'-CTTGTTGCATCGTTTCTT-3' \\
& F: 5'-CGTGATGGACTCTGGTGA-3' \\
$\beta$-actin & R: 5'-ACAGTGTTGGCATACAGGT-3' & \\
\hline
\end{tabular}

RNA extraction and 1st Strand cDNA Synthesis

Total RNA was isolated with RNAiso Plus according to the manufacturer's instructions. Purity and Quantitative OD260/280 of isolated RNA were quantified by spectrophotometry at 260 and $280 \mathrm{~nm}$, respectively, whereas the quality of the RNA was verified by agarose gel electrophoresis. The first-strand cDNA was performed with PrimeScript ${ }^{\mathrm{TM}}$ 1st Stand cDNA Synthesis Kit according to manufacturer's instructions. (Dalian Takara Company). Reverse transcription was performed on total RNA using Oligo-DT as the primer in a $20 \mu \mathrm{L}$ reaction volume. The cDNA reaction mixtures were diluted $1 / 10$ and stored in $-20^{\circ} \mathrm{C}$ freezer that were served as templates for PCR amplification.

PCR amplification

PCR amplification was conducted on a Mini PCR amplification machine (Thermo). The $25 \mu \mathrm{L}$ reaction contained $2.5 \mu \mathrm{L} 10 \times$ PCR Buffer, $1.5 \mu \mathrm{L}$ dNTP Mixture, $0.5 \mu \mathrm{L}$ TaKaRa TaqE, $0.5 \mu \mathrm{L}$ of each primer, $18.5 \mu \mathrm{L}$ ddH2O, $1 \mu \mathrm{L}$ cDNA sample.

PCR amplification of FAS cDNA fragments was performed using the following protocol: $10 \mathrm{~min}$ at $94^{\circ} \mathrm{C}, 35$ cycles consisting of $30 \mathrm{~s}$ at $94^{\circ} \mathrm{C}, 45 \mathrm{~s}$ at $52^{\circ} \mathrm{C}$ and $1 \mathrm{~min}$ at $72^{\circ} \mathrm{C}$, finally $10 \mathrm{~min}$ at $72^{\circ} \mathrm{C}$. PCR amplification of LPL cDNA fragments was performed using the following protocol: 10 min at $94^{\circ} \mathrm{C}, 30$ cycles consisting of $30 \mathrm{~s}$ at $94^{\circ} \mathrm{C}, 40 \mathrm{~s}$ at $53^{\circ} \mathrm{C}$ and $1 \mathrm{~min}$ at $72^{\circ} \mathrm{C}$, finally $10 \mathrm{~min}$ at $72^{\circ} \mathrm{C}$. PCR amplification of $\beta$-actin cDNA fragments was performed using the following protocol: $10 \mathrm{~min}$ at $94^{\circ} \mathrm{C}, 30$ cycles consisting of $30 \mathrm{~s}$ at $94^{\circ} \mathrm{C}, 30 \mathrm{~s}$ at $59^{\circ} \mathrm{C}$ and $1 \mathrm{~min}$ at $72^{\circ} \mathrm{C}$, finally $10 \mathrm{~min}$ at $72^{\circ} \mathrm{C}$.

Statistical analysis of relative expression amount of FAS and LPL mRNA

The signal strength of each electrophoresis bands was analyzed by the Gel-Pro analyzer software, and ratio with respectively corresponding to $\beta$-actin signal intensity indicates the relative expression 
of FAS mRNA and LPL mRNA.And then, FAS / $\beta$-actin and LPL / $\beta$-actin ratio were used for statistical analysis of relative expression amount of FAS and LPL mRNA.

\section{Statistical analysis}

All data were expressed as mean values \pm standard error (SE) and subjected to one-way analysis of variance (one-way ANOVA). Percentage data were arcsine transformed before analysis of variance. When there were significant differences, Duncan's multiple range tests were conducted among group means. The significant level was set as $P<0.05$. All statistical analyses were performed using the SPSS 17.0.

\section{Results}

Effects of dietary lipid levels on growth of common carp

Effects of dietary lipid levels on growth and feed utilization of common carp

After Five experimental diets were fed to triplicate groups of fish for 9 weeks, survival rate of each group carp ranged from $94.5 \%$ to $97.8 \%$. Therefore the experimental diets fed to common carp did not affect the values of the survival rate. Weight growth rate (WG) and specific growth rate (SGR) with increasing levels of dietary lipid decreased first and then increased and then decreased, but meanwhile Diet 4 (29.2/7.6) group was the highest and was significantly higher than Diet $5(28.3 / 9.4)$ group $(\mathrm{P}<0.05)$. The feed conversion ratio $(\mathrm{FCR})$ of common carp fed with Diet $4(29.2 / 7.6)$ were lowest and significantly lower than Diet 5 (28.3/9.4) group, but no significant difference $(\mathrm{P}>0.05)$ from the other treatment groups. The protein efficiency ratio (PER) of common carp fed with Diet 4 (29.2/7.6) were highest and significantly higher than Diet $2(31.1 / 4.0)$ group, but no significant difference $(\mathrm{P}>0.05)$ from the other treatment groups. (Table 3$)$

Table 3 Effects of dietary lipid levels on growth and feed utilization of common carp \%

\begin{tabular}{cccccc}
\hline $\begin{array}{c}\text { Diet No } \\
\text { (protein / lipid) }\end{array}$ & $\begin{array}{c}\text { Survival } \\
\text { rate }\end{array}$ & $\begin{array}{c}\text { Weight growth } \\
\text { rate(WG) }\end{array}$ & $\begin{array}{c}\text { Specific growth } \\
\text { rate(SGR) }\end{array}$ & $\begin{array}{c}\text { Feed conversion } \\
\text { ratio (FCR) }\end{array}$ & $\begin{array}{c}\text { Protein efficiency } \\
\text { ratio (PER) }\end{array}$ \\
\hline Diet 1 (32.0/2.1) & $94.45 \pm 3.85$ & $323.3 \pm 29.96^{\mathrm{ab}}$ & $2.29 \pm 0.11^{\mathrm{ab}}$ & $1.24 \pm 0.08^{\mathrm{ab}}$ & $2.46 \pm 0.15^{\mathrm{ab}}$ \\
Diet 2 (31.1/4.0) & $94.45 \pm 2.55$ & $291.9 \pm 23.87^{\mathrm{ab}}$ & $2.17 \pm 0.10^{\mathrm{ab}}$ & $1.38 \pm 0.09^{\mathrm{ab}}$ & $2.29 \pm 0.14^{\mathrm{b}}$ \\
Diet 3 (30.2/5.8) & $96.67 \pm 2.89$ & $311.4 \pm 28.65^{\mathrm{ab}}$ & $2.24 \pm 0.12^{\mathrm{ab}}$ & $1.27 \pm 0.14^{\mathrm{ab}}$ & $2.60 \pm 0.27^{\mathrm{ab}}$ \\
Diet 4 (29.2/7.6) & $97.33 \pm 0.28$ & $332.5 \pm 36.46^{\mathrm{a}}$ & $2.32 \pm 0.14^{\mathrm{a}}$ & $1.20 \pm 0.14^{\mathrm{b}}$ & $2.84 \pm 0.30^{\mathrm{a}}$ \\
\hline Diet 5 (28.3/9.4) & $97.76 \pm 0.12$ & $282.2 \pm 4.48^{\mathrm{b}}$ & $2.13 \pm 0.02^{\mathrm{b}}$ & $1.41 \pm 0.01^{\mathrm{a}}$ & $2.50 \pm 0.02^{\mathrm{ab}}$ \\
\hline
\end{tabular}

Effects of dietary lipid levels on body organs of common carp

With increasing dietary lipid levels, the condition factors (CF) of experimental common carp fed with five experimental diets increased gradually, but there was no significant difference among the treatment groups. Feeding common carp the experimental diets for 9 weeks did have a significant impact on hepatosomatic indexes (HSI). The hepatosomatic indexes (HSI) of common carp fed with Diet $5(28.3 / 9.4)$ were significantly higher than the other treatment groups $(P<0.05)$. The next were Diet $3(30.2 / 5.8)$ and Diet $4(29.2 / 7.6)$ groups, but there was no significant difference between two groups $(\mathrm{P}>0.05)$. The lowest was Diet 2 (31.1/4.0) group, but Diet 2 (31.1/4.0) group had no significant difference from Diet $1(32.0 / 2.1)(P>0.05)$. (Table 4$)$ 
Table 4 Effects of dietary lipid levels on body organs of common carp \%

\begin{tabular}{ccc}
\hline Diet No & Hepatosomatic indexes & Condition factors \\
$($ protein / lipid $)$ & $($ HIS $)$ & $($ CF $)$ \\
\hline Diet 1 (32.0/2.1) & $1.42 \pm 0.15^{\text {cd }}$ & $2.78 \pm 0.31$ \\
Diet 2 (31.1/4.0) & $1.36 \pm 0.06^{\mathrm{d}}$ & $2.85 \pm 0.42$ \\
Diet 3 (30.2/5.8) & $1.58 \pm 0.04^{\mathrm{b}}$ & $2.67 \pm 0.28$ \\
Diet 4 (29.2/7.6) & $1.55 \pm 0.06^{\mathrm{bc}}$ & $2.87 \pm 0.12$ \\
Diet 5 (28.3/9.4) & $1.75 \pm 0.07^{\mathrm{a}}$ & $2.86 \pm 0.37$ \\
\hline
\end{tabular}

Effects of dietary lipid levels on activities of related metabolic enzymes of common carp Effects of dietary lipid levels on activities of related metabolic enzymes of hepatopancreas

The activities of lipoprotein lipase, hepatic lipase and total lipase of hepatopancreas of common carp fed experimental diets with increasing lipid levels increased significantly, and significantly higher activities of them were noted in the hepatopancreas of the fish from the Diet 5 (28.3/9.4) group in comparison with the other dietary treatments $(P<0.05)$. Significant differences in the activities of total lipase were noted among groups in all of the hepatopancreas of the fish $(P<0.05)$. With increasing dietary lipid levels, The activities of fatty acid synthetase of common carp decreased significantly, but just the experimental diets with increasing lipid levels of $7.6 \%$ and $9.4 \%$ fed to the common carp made the activities of fatty acid synthetase decrease significantly gradually, and there was no significant difference between two groups $(P>0.05)$.(Table 5)

Table 5 Effects of dietary lipid on activities of metabolic enzymes of hepatopancreas U/g

\begin{tabular}{ccccc}
\hline $\begin{array}{c}\text { Diet. No } \\
\text { (protein/lipid) }\end{array}$ & Lipoprotein lipase & Hepatic lipase & Total lipase & fatty acid synthetase \\
\hline Diet 1 (32.0/2.1) & $3.45 \pm 0.13^{\mathrm{d}}$ & $1.43 \pm 0.09^{\mathrm{d}}$ & $4.89 \pm 0.11^{\mathrm{e}}$ & $2.60 \pm 0.03^{\mathrm{a}}$ \\
Diet 2 (31.1/4.0) & $4.30 \pm 0.18^{\mathrm{c}}$ & $1.43 \pm 0.05^{\mathrm{d}}$ & $5.74 \pm 0.13^{\mathrm{d}}$ & $2.55 \pm 0.06^{\mathrm{a}}$ \\
Diet 3 (30.2/5.8) & $4.49 \pm 0.09^{\mathrm{c}}$ & $2.96 \pm 0.06^{\mathrm{c}}$ & $7.45 \pm 013^{\mathrm{c}}$ & $2.51 \pm 0.05^{\mathrm{a}}$ \\
Diet 4 (29.2/7.6) & $5.06 \pm 0.06^{\mathrm{b}}$ & $4.27 \pm 0.03^{\mathrm{b}}$ & $9.33 \pm 0.06^{\mathrm{b}}$ & $1.86 \pm 0.08^{\mathrm{b}}$ \\
Diet 5 (28.3/9.4) & $14.45 \pm 0.13^{\mathrm{a}}$ & $11.12 \pm 0.13^{\mathrm{a}}$ & $25.51 \pm 0.23^{\mathrm{a}}$ & $1.75 \pm 0.71^{\mathrm{b}}$ \\
\hline
\end{tabular}

Effects of dietary lipid levels on activities of related metabolic enzymes of kidney

As can be seen from Table 6, with increasing dietary lipid levels, there were significant increases in the activities of lipoprotein lipase, hepatic lipase and total lipase of kidney of common carp, and also significantly higher activities of them were noted in the kidney of the fish from the Diet $5(28.3 / 9.4)$ group compared to the other dietary treatments $(P<0.05)$. But no significant differences were noted in the activities of them in the kidney between Diet $3(30.2 / 5.8)$ and Diet $4(29.2 / 7.6)$ groups $(P>0.05)$. The activities of fatty acid synthetase of kidney of common carp fed experimental diets with increasing lipid levels decreased significantly, but just the activities of fatty acid synthetase of common carp fed experimental diets with lipid levels of $7.6 \%$ and $9.4 \%$ decreased significantly gradually, and there was no significant difference between two groups $(P>0.05)$. 
Table 6 Effects of dietary lipid on activities of metabolic enzymes of kidney U/g

\begin{tabular}{ccccc}
\hline $\begin{array}{c}\text { Diet. No } \\
\text { (protein/lipid) }\end{array}$ & Lipoprotein lipase & Hepatic lipase & Total lipase & fatty acid synthetase \\
\hline Diet 1 (32.0/2.1) & $0.26 \pm 0.05^{\mathrm{d}}$ & $0.07 \pm 0.03^{\mathrm{c}}$ & $0.33 \pm 0.03^{\mathrm{d}}$ & $1.49 \pm 0.05^{\mathrm{a}}$ \\
Diet 2 (31.1/4.0) & $0.49 \pm 0.05^{\mathrm{c}}$ & $0.12 \pm 0.03^{\mathrm{c}}$ & $0.49 \pm 0.08^{\mathrm{c}}$ & $1.43 \pm 0.09^{\mathrm{a}}$ \\
Diet 3 (30.2/5.8) & $0.77 \pm 0.07^{\mathrm{b}}$ & $0.23 \pm 0.07^{\mathrm{b}}$ & $1.00 \pm 0.06^{\mathrm{b}}$ & $1.41 \pm 0.07^{\mathrm{a}}$ \\
Diet $4(29.2 / 7.6)$ & $0.80 \pm 0.03^{\mathrm{b}}$ & $0.23 \pm 0.05^{\mathrm{b}}$ & $1.03 \pm 0.07^{\mathrm{b}}$ & $0.76 \pm 0.08^{\mathrm{b}}$ \\
Diet 5 (28.3/9.4) & $1.10 \pm 0.06^{\mathrm{a}}$ & $0.33 \pm 0.03^{\mathrm{a}}$ & $1.43 \pm 0.03^{\mathrm{a}}$ & $0.65 \pm 0.10^{\mathrm{b}}$ \\
\hline
\end{tabular}

Effects of dietary lipid on expression of FAS and LPL mRNA of common carp

According to the increasing tendency of the activities of the related lipid metabolism enzyme with increasing dietary lipid levels, at the end of 9-week feeding trials, the fish were fasted for $48 \mathrm{~h}$ and then refed. Expressions of FAS and LPL mRNA of hepatopancreas and kidney were examined at 0, 3, $6,12,24$ and $48 \mathrm{~h}$ after refeeding low lipid group of Diet $1(32.0 / 2.1)$ and high lipid group of Diet 5 (28.3/9.4) using the semi-quantitative RT-PCR. And then the study has made the significant analysis for the results.

Effects of dietary lipid on expression of FAS and LPL mRNA of hepatopancreas

As can be seen from Fig. 1, Table 7 and Table 8, at 3 h, 6 h, 12 h, $48 \mathrm{~h}$ after refeeding, each group average of expression abundance of FAS and LPL mRNA had certain fluctuation, but there was no significant difference between two groups $(P>0.05)$, while at $24 \mathrm{~h}$ after refeeding and $48 \mathrm{~h}$ after fasting, the expression abundance of FAS mRNA of low lipid group of Diet 1 (32.0/2.1) was significantly higher than high lipid group of Diet $5(28.3 / 9.4)(P<0.05)$, and the expression abundance of LPL mRNA of low lipid group of Diet 1 (32.0/2.1) was significantly lower than high lipid group of Diet $5(28.3 / 9.4)(P<0.05)$. Refeeding common carp the experimental diets of low lipid and high lipid in different time periods did have a significant impact on the expression levels of FAS and LPL mRNA of the hepatopancreas tissue of common carp $(P<0.05)$. In Diet $1(32.0 / 2.1)$ group, , the expression abundance of FAS mRNA significantly decreased $(P<0.05)$ at $3 \mathrm{~h}$ to $6 \mathrm{~h}$ after refeeding, and significantly increased at $12 \mathrm{~h}$ to $24 \mathrm{~h}$ after refeeding $(P<0.05)$, while at $3 \mathrm{~h}$ to $12 \mathrm{~h}$ after feeding, expression abundance of LPL mRNA increased, and decreased at $24 \mathrm{~h}$ to $48 \mathrm{~h}$ after feeding, but not significant $(P>0.05)$. In Diet $5(28.3 / 9.4)$ group, the expression abundance of FAS mRNA at $6 \mathrm{~h}$ after refeeding decreased to minimum, and was significantly lower than in other various time periods $(P$ $<0.05$ ), and then presented an upward trend, while the expression abundance of LPL mRNA at $12 \mathrm{~h}$ after refeeding increased to the highest, and was significantly higher than the other various time periods $(P<0.05)$, and then presented a downward trend.

Table 7 Effects of fasting and refeeding different lipid diets on the expression levels of FAS mRNA of the hepatopancreas tissue of common carp

\begin{tabular}{lcccccc}
\hline \multirow{2}{*}{$\begin{array}{c}\text { Diet No. } \\
\text { (protein/lipid) }\end{array}$} & Starved & \multicolumn{5}{c}{ Postprandial time } \\
\cline { 3 - 7 } & & $3 \mathrm{~h}$ & $6 \mathrm{~h}$ & $12 \mathrm{~h}$ & $24 \mathrm{~h}$ & $48 \mathrm{~h}$ \\
\hline Diet 1 (32.0/2.1) & $0.98 \pm 0.13^{\mathrm{Aa}}$ & $0.44 \pm 0.07^{\mathrm{Ac}}$ & $0.06 \pm 0.02^{\mathrm{Ad}}$ & $0.46 \pm 0.12^{\mathrm{Ac}}$ & $0.62 \pm 0.10^{\mathrm{Ab}}$ & $0.64 \pm 0.10^{\mathrm{Ab}}$ \\
Diet 5 (28.3/9.4) & $0.56 \pm 0.07^{\mathrm{Ba}}$ & $0.39 \pm 0.07^{\mathrm{Ab}}$ & $0.05 \pm 0.03^{\mathrm{Ad}}$ & $0.23 \pm 0.04^{\mathrm{Ac}}$ & $0.35 \pm 0.1^{\mathrm{Bbc}}$ & $0.41 \pm 0.11^{\mathrm{Ab}}$ \\
\hline $\begin{array}{l}\text { Note: Different uppercase letters between the groups independent samples t test within the same time significant difference }(P<0 \text { 05.) } \\
\text { Marked with different column data shoulder lowercase letters indicate significant difference }(\mathrm{P}<0.05) \text {, with the following tables. }\end{array}$
\end{tabular}


Table 8 Effects of fasting and refeeding different lipid diets on the expression levels of LPL mRNA of the hepatopancreas tissue of common carp

\begin{tabular}{ccccccc}
\hline \multirow{2}{*}{$\begin{array}{c}\text { Diet No. } \\
\text { (protein/lipid) }\end{array}$} & Starved & \multicolumn{5}{c}{ Postprandial time } \\
\cline { 3 - 7 } & & $3 \mathrm{~h}$ & $6 \mathrm{~h}$ & $12 \mathrm{~h}$ & $24 \mathrm{~h}$ & $48 \mathrm{~h}$ \\
\hline Diet 1 (32.0/2.1) & $0.39 \pm 0.14^{\mathrm{Bb}}$ & $0.76 \pm 0.17^{\mathrm{Aab}}$ & $0.82 \pm 0.20^{\mathrm{Aab}}$ & $1.21 \pm 0.27^{\mathrm{Aa}}$ & $0.51 \pm 0.09^{\mathrm{Bb}}$ & $0.73 \pm 0.11^{\mathrm{Aab}}$ \\
Diet 5 (28.3/9.4) & $1.09 \pm 0.06^{\mathrm{Ab}}$ & $1.24 \pm 0.06^{\mathrm{Ab}}$ & $1.42 \pm 0.10^{\mathrm{Aab}}$ & $1.70 \pm 0.12^{\mathrm{Aa}}$ & $1.40 \pm 0.10^{\mathrm{Aab}}$ & $1.06 \pm 0.03^{\mathrm{Ab}}$ \\
\hline
\end{tabular}
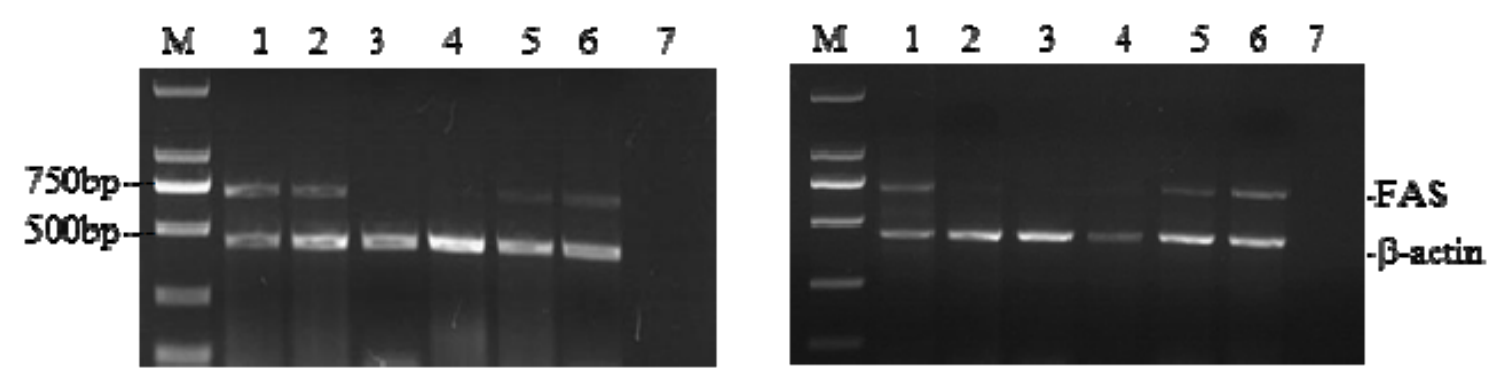

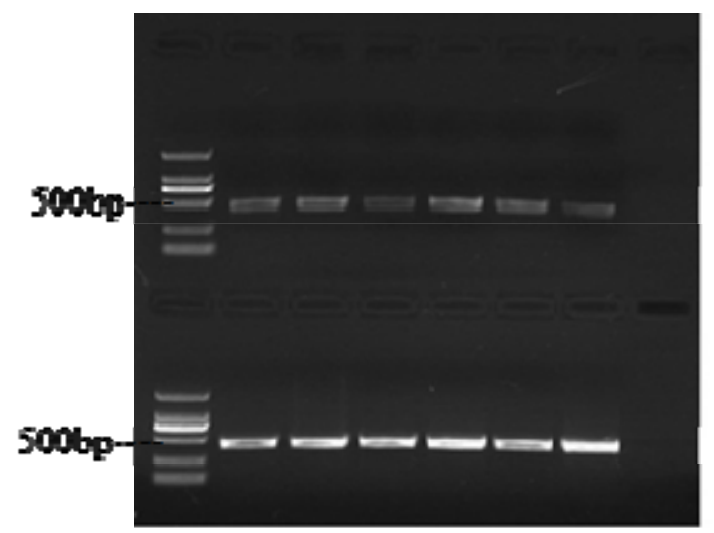

A

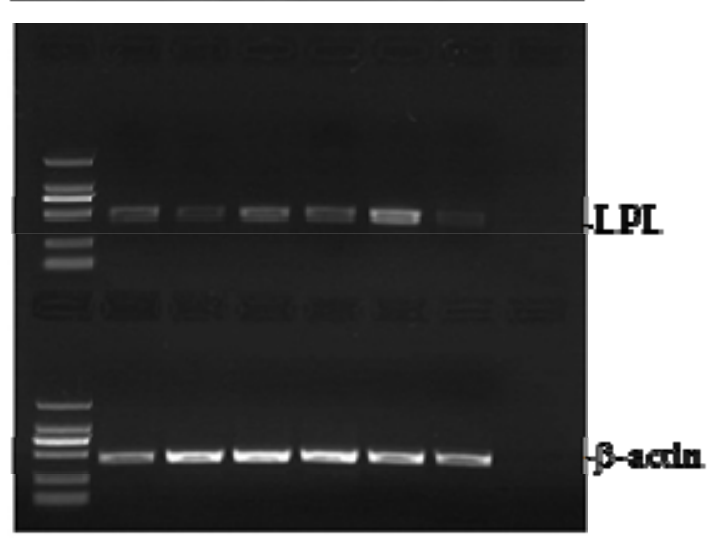

B

Fig. 1 Representative agarose gel electrophoresis according to the expression of FAS and LPL mRNA in the hepatopancreas after refeeding the experimental diets of Diet 1 and Diet 5

1: $48 \mathrm{~h}$ after fasting; 2-6: $3 \mathrm{~h}, 6 \mathrm{~h}, 12 \mathrm{~h}, 24 \mathrm{~h}, 48 \mathrm{~h}$ after refeeding; 7 : blank; M: MarkerDL2000; A: Refeeding Diet 1; B:Refeeding Diet 5

Effects of dietary lipid on expression of FAS and LPL mRNA of kidney

As can be seen from Table 9 and Fig. 2, at $48 \mathrm{~h}$ after fasting and after refeeding Diet $1(32.0 / 2.1)$ and Diet $5(28.3 / 9.4)$, the expression of FAS mRNA in the kidney was not detected. At $6 \mathrm{~h}$ to $48 \mathrm{~h}$ after refeeding, the expression abundance of FAS mRNA of low lipid group of Diet $1(32.0 / 2.1)$ was significantly lower than high lipid group of Diet $5(28.3 / 9.4)(P<0.05)$. Refeeding common carp the experimental diets of low lipid and high lipid in different time periods did have a significant impact on the expression levels of LPL mRNA of the kidney of common carp $(P<0.05)$. In Diet $1(32.0 / 2.1)$ group, the expression abundance of LPL mRNA at $12 \mathrm{~h}$ after refeeding increased to the highest, and was significantly higher than the other various time periods $(P<0.05)$. In Diet $5(28.3 / 9.4)$ group, the expression abundance of LPL mRNA at $24 \mathrm{~h}$ after refeeding increased to the highest, and was significantly higher than the other various time periods except $12 \mathrm{~h}$ after refeeding $(P<0.05)$. 
Table 9 Effects of fasting and refeeding different lipid diets on the expression levels of LPL mRNA of the kidney of common carp

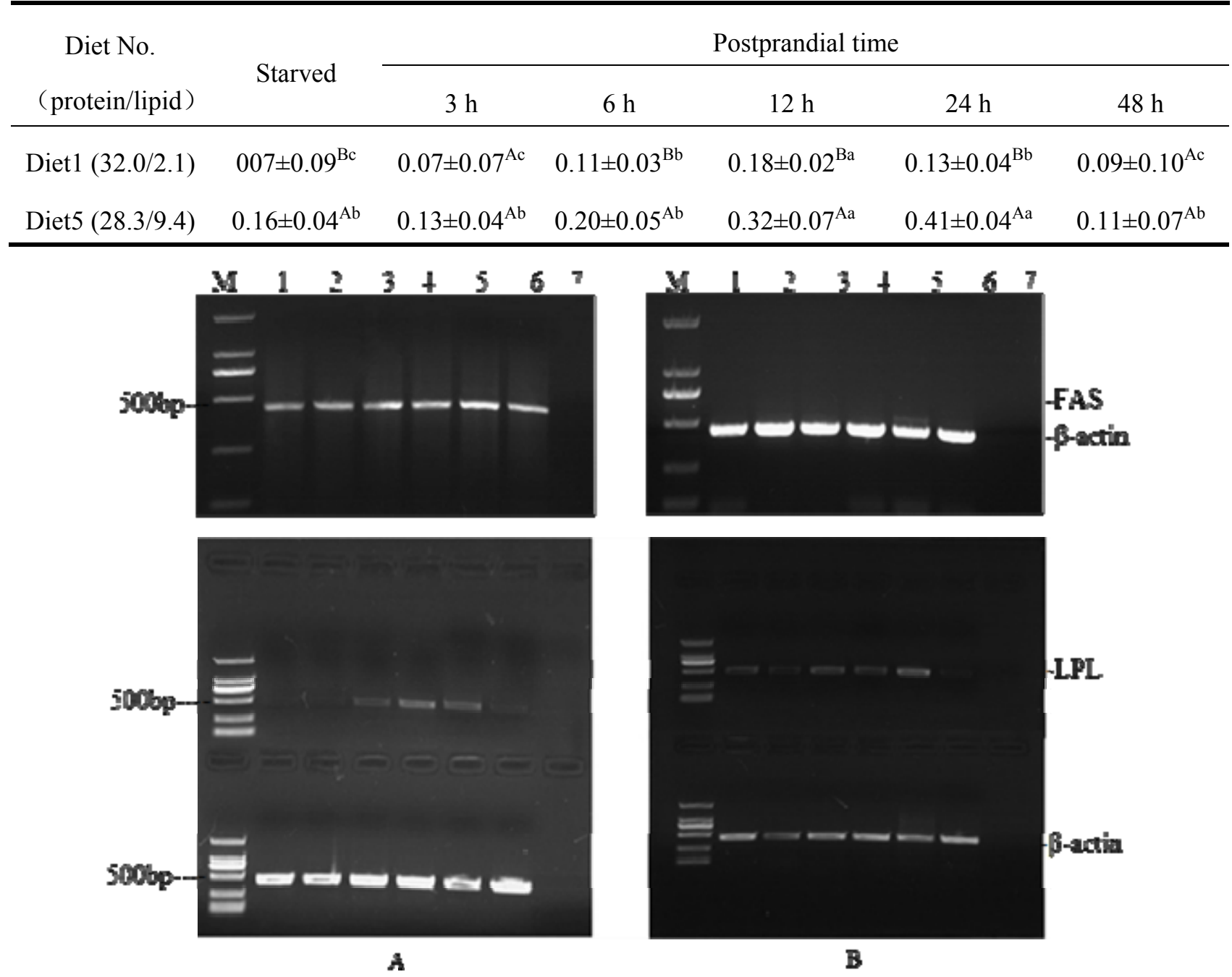

Fig. 2 Representative agarose gel electrophoresis according to the expression of FAS and LPL mRNA in the kidney after refeeding the experimental diets of Diet 1 and Diet 5

1: $48 \mathrm{~h}$ after fasting; 2-6: $3 \mathrm{~h}, 6 \mathrm{~h}, 12 \mathrm{~h}, 24 \mathrm{~h}, 48 \mathrm{~h}$ after refeeding; 7: blank; M: MarkerDL2000;

A: Refeeding Diet 1; B:Refeeding Diet 5

\section{Discussion}

\section{Effects of dietary lipid levels on growth of common carp}

Dietary lipid plays an important role on the maintenance of growth in commercial fish diet as a source of energy and essential fatty acids [9]. When dietary lipid level is excessively low, fish will make the protein used to generate energy instead of used for the growth in order to maintain the survival. Therefore, to increase the dietary lipid level will contribute to improving the protein efficiency and promoting the growth of fish. Under these experimental conditions, the experimental fish from the Diet $4(29.2 / 7.6)$ group were characterized by the highest values of weight growth rate, specific growth rate, feed conversion and protein efficiency in comparison with the other groups. However, when the lipid level was higher than the $7.6 \%$ lipid level, protein efficiency did not continue to increase, and the weight growth rate and specific growth rate of the high-lipid group was significantly lower than the $7.6 \%$ lipid group $(\mathrm{P}<0.05)$. This results indicated that to further improve the level of lipid failed to save the protein to promote the growth of fish. Thus, the appropriate level of dietary lipid can promote growth and improve breeding efficiency.

The liver occupies a very important position in the metabolism of carbohydrates, lipids and proteins and other nutrients, and is also an important nutrient storage sites, which is why the 
hepatosomatic indexes (HSI) of fish is treated as very sensitive indicators for the long-term and the short-term nutrition way [10]. In this study, the hepatosomatic indexes (HSI) of experimental common carp fed with five experimental diets increased gradually with increasing dietary lipid levels, and there were significant differences among the treatment groups $(P<0.05)$. Wang Aimin found that Feeding Carassius auratus gibelio the diets with different lipid levels did have a significant impact on hepatosomatic indexes (HSI) [9].

\section{Effects of dietary lipid levels on activities of related metabolic enzymes of common carp}

The amounts and the activities of fatty acid synthase (FAS) play an important role on controlling the generation and the deposition of the lipid of animal body. One of the most important factors affecting the level of FAS activity is the nutritional factor of dietary[11-13]. For instance, Dias et al [14] found that high soybean meal diet can reduce the FAS activity of European perch liver; Tian Juan et al [15] reported that adding the appropriate level of carnitine significantly reduced the FAS activity of the liver of fish. Meanwhile related research also shows that the higher the dietary lipid level is, the lower the FAS activity is [16]. In this experiment, the FAS activities of the hepatopancreas and kidney of common carp was in negative correlation to dietary lipid levels, and the FAS activities of the hepatopancreas decreased significantly $(\mathrm{P}<0.05)$, indicating the dietary lipid levels failed to produce the induction to the secretion of FAS activity.

With the changes in nutritional status, the hepatopancreas are capable of making the regulatory changes for the lipid deposition. Fish have several lipases including lipoprotein lipase (LPL) and hepatic lipase (HL), collectively referred to as total lipase, all of which play critical roles in digesting dietary lipids. Zhang Chunnuan et al [17] reported that with increasing lipid levels, the dietary lipid levels within the range of $2.71-16.91 \%$ can significantly improve the activities of hepatic lipoprotein lipase, hepatic esterase of Chelon haematocheilus. However, Xiang Xiao reported that with increasing lipid levels, the dietary lipid levels ranged from $2.71 \%$ to $9.14 \%$ can significantly increase the activities of hepatic lipoprotein lipase, hepatic esterase and total lipase of juvenile Onychostoma sima, but the dietary lipid levels more than $9.14 \%$ made these activities decreased. A possible reason for the difference between the two studies was that different fish species were used. Chelon haematocheilus belongs to the fish which has the stomach, and the gastric lipase in the stomach helps digest lipids, thereby reducing lipid deposition, while juvenile Onychostoma sima belongs to the fish which does not have the stomach, and the digestion of lipid mainly depends on chemical digestion of the liver. In this study, the activities of hepatopancreas lipoprotein lipase, liver esterase and total esterase of common carp increased with increasing dietary lipid level, and the $9.4 \%$ lipid group had the highest activities of hepatopancreas ipoprotein lipase (LPL) and hepatic lipase (HL) and total lipase of common carp, consistent with the reports of Xiang Xiao for juvenile Onychostoma sima. But the $9.4 \%$ level has the highest lipid level, so we did not get the dietary lipid levels which made the activities of lipoprotein lipase (LPL) and hepatic lipase (HL) and total lipase decrease and will be examined in-depth in future studies. In addition, this study also found that with the increase of dietary lipid levels, the activities of lipoprotein lipase (LPL) and hepatic lipase (HL) and total lipase in the kidney also showed an increasing trend, but the current research on the relationship between fish and lipid metabolism in the kidney relatively rare,so the specific regulatory mechanisms will require further study.

\section{Effects of dietary lipid on expression of FAS and LPL mRNA of common carp}

In the process of fatty acid synthesis and catabolism of fish, there is , respectively, one key enzyme, namely fatty acid synthasis and lipoprotein lipase. Dietary lipid levels promote hepatic LPL mRNA expression in dark barbel catfish [18] and in red sea bream [19], but decrease hepatic FAS mRNA expression in GIFT tilapia. Our study further demonstrated that high dietary lipid did not only induce and regulate the expression of hepatopancreas LPL, but also suppressed and regulate the expression of hepatopancreas FAS. However, Liang et al. [20] found that dietary lipid levels did not significantly affect the expression level of LPL mRNA in red sea bream. One possible explanation for these differing results is that Liang et al. used a shorter sampling time after feeding.

In this study, the effects of refeeding on the expressions levels of FAS and LPL mRNA of hepatopancreas and kidney were analyzed at $0,3,6,12,24$ and $48 \mathrm{~h}$ after refeeding and fasting using 
the semi-quantitative RT-PCR. Our results demonstrated that the lowest expression levels of FAS mRNA of hepatopancreas appeared at $6 \mathrm{~h}$ after refeeding low lipid group of Diet $1(32.0 / 2.1)$ and high lipid group of Diet 5 (28.3/9.4), and the highest expression levels of LPL mRNA of hepatopancreas appeared at $12 \mathrm{~h}$ after refeeding. These results indicate that the expression of hepatopancreas FAS and LPL is regulated by fasting or refeeding. Our results were consistent with those of Ji Hong et al. [21] and partially consistent with those of Wang Aimin et al. [22] and Oku et al. [23]. A possible reason for the variation was a difference between fasting time and refeeding; different fish species were used. Also, these studies were performed in different seasons. In addition, this study also found that the FAS mRNA expression of the kidney of common carp refed with Diet $1(32.0 / 2.1)$ and Diet 5 (28.3/9.4) after fasting was not detected, indicating that the expression of kidney FAS mRNA was not regulated by fasting or refeeding. The highest expression levels of LPL mRNA of kidney appeared at $12 \mathrm{~h}$ after refeeding Diet 1 (32.0/2.1), while the highest expression levels of LPL mRNA of kidney appeared at $24 \mathrm{~h}$ after refeeding Diet 5 (28.3/9.4), indicating that the expression of kidney LPL mRNA was induced and regulated by fasting or refeeding. But understanding the exact molecular regulatory mechanisms involved will require further study.

\section{Conclusions}

(1) Under these experimental conditions, the results indicated that appropriate dietary lipid levels can increase the utilization of feed nutrients, but when reaching or exceeding $9.4 \%$, the dietary lipid levels will make some indicators appear abnormal and then affect the growth of fish.

(2) The expression of hepatopancreas FAS and LPL is regulated by fasting or refeeding, while the expression of kidney FAS and LPL did not change in a regular way, indicating the expression of kidney FAS and LPL is not regulated by fasting or refeeding.

\section{Acknowledgements}

This work was financially supported by the key technologies R\&D program of Tianjin (13ZCZDNC00900), Tianjin Research Program of Application Foundation and Advanced Technology (14JCQNJC15100), Tianjin Innovative Research Team (TD12-5018), and National Natural Science Foundation of China (31402313).

\section{References}

[1] Cho S.H., S.M. Lee, S.M. Lee and J.H. Lee: Aquaculture Nutrition. Forum Vol. 11 (2005), p. 235-240

[2] Zhenyu Du, Yongjian Liu, Lixia Tian, et al: Aquaculture Nutrition. Forum Vol. 11 (2005), p. 139-146 [In Chinese]

[3] Pedro B, Beatriz O, Susana C, et al: British Journal of Nutrition. Forum Vol.102 (2009), p. 1007-1014

[4] Guangming Han: Effects of Dietary Lipid Levels on Growth, lipid Deposition, fatty Acid Profiles and fatty Acid Synthase of GIFT Strain Nile Tilapia Oreochromis niloticus. Master thesis: Nanjing Agricultural University, 2009 [In Chinese]

[5] Shearer K D: Aquaculture. Forum Vol. 119 (1994), p. 63-88

[6] Chou B S and Shiau S Y: Aquaculture. Forum Vol.143 (1996), p. 185-195

[7] Liping Song, Bo Han, Shuquan Mao, et al: Journal of Guangdong Ocean University. Forum Vol. 30 (2010), p. 13-17 [In Chinese] 
[8] Oscar: Effect of Dietary Lipids Source on the Lipoprotein Lipase and fatty Acid Synthase Gene Expression of Common carp (Cyprinus carpio) . Master thesis: Southwest University, 2012 [In Chinese]

[9] Aimin Wang, Pao Xu, Pei Li, et al: Forum Vol. 17 (2008), p. 661-667 [In Chinese]

[10] Zhenying Jiang, Zhiyhai Jia, Yunsuo Guo, et al: Chinese Journal of Animal Nutrition. Forum Vol. 19 (2007), p. 86-90 [In Chinese]

[11] Jantrarotai, W. P. Sitasi and S. Rajchapakdee: Aquaculture. Forum Vol.127 (1994), p. 61-68

[12] Clarke S. D. and M. K. Armstrong, D. B. Jump: Journal of Nutrition. Forum Vol. 120 (1990), p. 218-224

[13] Keke Zheng, Xiaoming Zhu, Dong Han, et al: Acta Hydrobiologica Sinica. Forum Vol. 34 (2010), p. 816-821 [In Chinese]

[14] Juan Tian, Xiangjun Leng, Xiaoqi Lin, et al: Journal of Fisheries of China. Forum Vol. 33 (2009), p. 295-302 [In Chinese]

[15] Dias.J, Alvarez.MJ, AlzelJ et al: Comparaive Biochemistry and Physiology. Forum Vol. 142 (2005), p. 19-31

[16] Xiao Xiang, Xinghua Zhou, Jian Chen, et al: Journal of Fisheries of China.. Forum Vol. 37 (2013), p. 1350-1355 [In Chinese]

[17] Chunnuan Zhang, Aimin Wang, Wenbin Liu, et al: Journal of Fishery Sciences of China. Forum Vol. 20 (2013), p. 108-115 [In Chinese]

[18] Keke Zheng, Xiaoming Zhu, Dong Han, et al: Aquacult Int. Forum Vol. 21 (2013), p. 1219-1232

[19] Xufang Liang, Oku H, Ogata HY, et al: Comparaive Biochemistry and Physiology A: Mol Integr Physiol. Forum Vol. 131 (2013), p. 335-342

[20] Xufang Liang, Junjie Bai, Haihua Lao, et al: Oceanologia et Limnologia Sinica. Forum Vol. 34 (2012), p. 625-631

[21] Aimin Wang, Guangming Han, Xinjian Wei, et al: Journal of Fisheries of China.. Forum Vol. 34 (2010), p, 1113-1119

[22] Hong Ji, Shangshun Su, Qian Liu, et al: Journal of Fisheries of China. Forum Vol. 33 (2009), p, 980-985

[23] Oku H, Koizumi N, Okumura T, et al: Comparaive Biochemistry and Physiology B: Biochemistry Mol Biol. Forum Vol. 145 (2010), p. 168-178 